The S.Paulo magazine features pictures of São Paulo state taken during the administration of State Governor Armando de Salles Oliveira (1935-1936). Writers Cassiano Ricardo and Menotti del Picchia, from the dissident group of São Paulo Modernism, were in charge of this publication aesthetically and ideologically. The magazine montages were inspired by the Russian Constructivist and German Dadaist photomontages. The magazine exhibits a modern visual discourse, yet a conservative ideology based on the Sao Paulo's coIonial past. The publication team was also composed by the photographers Benedito Junqueira Duarte and Theodor Preising as well as the engraver Lívio Abramo. Keywords: photomontage, conservative ideology, modern aesthetic 


\section{Fotomontagem: ordem da subversão. Análise da revista S.Paulo (1936)}

Marina

TAKAMI

A revista S.Paulo apresenta imagens do Estado paulista durante a administração do governador Armando de Salles Oliveira (1935-1936). Dirigiam a publicação, estética e ideologicamente, os escritores Cassiano Ricardo e Menotti del Picchia, ligados ao grupo dissidente do modernismo de São Paulo. As montagens da revista foram inspiradas pelas fotomontagens construtivista russa e dadaísta alemã. A S.Paulo privilegia o discurso visual de aparência moderna ao mesmo tempo em que expõe ideais conservadores baseados no passado colonial paulista. Participaram da equipe técnica do periódico os fotógrafos Benedito Junqueira Duarte e Theodor Preising e o gravador Lívio Abramo.

Palavras-chave: fotomontagem, ideologia conservadora, estética moderna. 
A revista S.Paulo é um exemplo singular do tema do bandeirantismo transposto em fotografias. O formato da Revista , surgida em meados da década de 1930, permite-nos adotar duas principais linhas de interpretação do periódico, a ideologia da marcha e a destacada solução gráfica de caráter moderno da S.Paulo.

A ideologia difundida pela Revista tem como base a historiografia paulista de fins do século XIX e começo do XX, que atuou sobre a construção da identidade nacional de cunho fortemente regional. O passado colonial de São Paulo foi reinventado por um grupo de intelectuais a partir da visão positiva e heróica da atuação dos antigos bandeirantes. Para a compreensão da ideologia da revista S.Paulo, o conceito de "marcha para oeste" é entendido do resgate histórico à modernização do tema; adota-se a ideologia da marcha, cuja idéia de movimento hierárquico, progressivo e de ocupação é coerente com as temáticas das reportagens da Revista e com a própria forma que se dá a ela, que agrega inclusive uma função modernizadora. Entende-se, então, por ideologia da marcha a recolocação do passado colonial paulista e a difusão dos predicados do antigo bandeirante como síntese da origem da fundação da nação e do desenvolvimento de São Paulo; esta ideologia encontra fundamento na historiografia territorialista e no pensamento conservador do grupo Verde-Amarelo. A força do bandeirantismo como tema de propaganda paulista reforçou-se nos anos 1930 com as noções de desbravamento e heroísmo expandidas para diferentes esferas e grupos sociais. Nos anos 1920 o termo bandeirante era restrito, durante a propaganda do Movimento Constitucionalista de 1932 ele se expandiu e, com o advento do Estado Novo, o poeta Cassiano Ricardo (1895-1974) nacionalizou o termo ao atuar como ideólogo do regime nos anos 1940.

As formas específicas de construção do discurso na revista S.Paulo estão alicerçadas nas funções e nos objetivos atribuídos ao periódico. O conteúdo era controlado de perto pelos diretores Cassiano Ricardo e Menotti del Picchia (1892-1988), membros fundadores dos grupos Verde-Amarelo, Anta e Bandeira, todos eles surgidos em defesa do nacionalismo na arte e 
na cultura mostrando-se ufanistas desde a origem e pendendo rapidamente a extremismos políticos de direita. Na configuração formal da S.Paulo a imagem foi eleita pelos diretores como o elemento principal do periódico. O discurso visual na Revista é muito bem cuidado, desde a escolha da técnica a ser usada (rotogravura) até a eleição dos técnicos da redação, que rompe fronteiras ideológicas e políticas. Cassiano Ricardo, principal articulador da Revista, reuniu uma equipe técnica bastante capaz e soube aproveitar os potenciais artísticos e técnicos dos fotógrafos Benedito Junqueira Duarte, o Vamp (1910-1995), e Theodor Preising (1883-1962) e do gravador Lívio Abramo (1903-1992). Este último era perseguido pelo governo provisório de Getúlio Vargas (1882-1954) devido a sua postura política alinhada à extrema esquerda, o que o contrapunha aos diretores da Revista. Houve um diálogo entre Cassiano Ricardo e Abramo nas décadas de 1930 e 1940; a razão que os separava foi, de certo modo, a mesma que uniu seus trabalhos naquele momento. A política, mesmo que de formas diversas, esteve presente nas preocupações artísticas de ambos e é significativa para o conhecimento de suas produções. Lívio Abramo colaborou com Ricardo ilustrando algumas de suas obras literárias, dentre elas o livro em prosa "Marcha para Oeste: a influência da Bandeira na formação social e política do Brasil", de 1940, no qual o autor fundamenta e justifica o governo autoritário do Estado Novo. Nesta obra, onde o interesse ideológico parece prevalecer, Cassiano Ricardo não deixou de imprimir-Ihe uma condição artística e as ilustrações de Abramo parecem estar em consonância com o texto.

A S.Paulo não é propriamente um periódico de propaganda política, mas sim, uma revista com implicações na política do período em que surgiu. Lembremos que a técnica não é neutra e que as escolhas não são feitas ao acaso. A revista S.Paulo possuía um projeto que incluía recursos propagandísticos; a presença ou a ausência de determinados elementos seguiu um roteiro ideológico. O tom, a expressividade, o ritmo e a intensidade do discurso podem cativar o leitor de modo que, talvez, o conteúdo em si seja menos relevante que a própria forma que se dá a ele. No caso da revista S.Paulo, ela foi recebida com en- 
tusiasmo na época do seu lançamento principalmente pelo seu aspecto formal baseado no uso da imagem fotográfica e da fotomontagem e numa diagramação moderna. Nota-se isto na reação de um correspondente internacional, Edward A. Ch.-Walden (Daily Telegraph de Londres), de passagem por São Paulo, que destaca, em depoimento publicado no exemplar 08, a visualidade como primeiro foco de atração da Revista: "Poucas horas depois da minha chegada ao Brasil, fui explorar as ruas; a minha atenção de jornalista voltou-se antes de tudo para as bancas. A primeira coisa que encantou meus olhos foram as capas atrativas da 'SÃO PAULO'" .
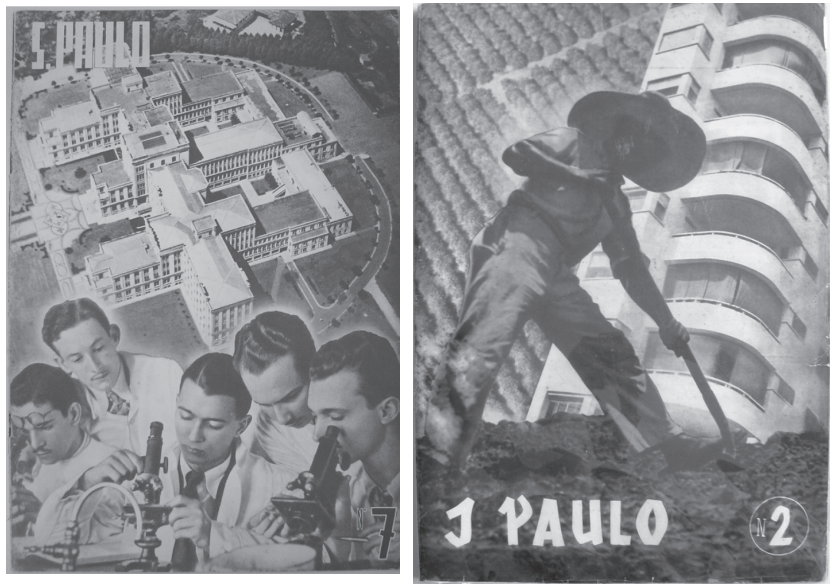

FIGURA 01 - capas S.Paulo fevereiro de 1936 S.Paulo, julho de 1936 (31,5cm X $45 \mathrm{~cm}$ aprox.). : Instituto de Estudos Brasileiros, IEB/USP.

A ênfase no

discurso visual da

Revista, em que o texto complementa a imagem, faz com que a publicação atinja leitores letrados, analfabetos e estrangeiros. Contudo, a elaboração textual não é descuidada pela redação, ao contrário, há reportagens em dois idiomas (português e inglês) e no espaço dedicado aos editoriais e publicação de depoimentos sobre a Revista a palavra escrita é priorizada. Além das fotografias, dados numéricos, mapas e gráficos atuam na busca por uma exposição objetiva do Estado; a existência destas diferentes formas de transmissão da informação certamente amplia o público leitor do periódico.

O governador Armando de Salles Oliveira (1887-1945) parece não ter se envolvido diretamente no enfoque ideológico da Revista, porém, por meio do apoio institucional e financeiro 
dava seu aval à redação. Os profissionais gráficos trabalhavam de modo a satisfazer as idéias dos diretores, que não eram colocadas com ênfase política e sim em favor da cultura e da inteligência de São Paulo e do país. A redação contava com um terceiro diretor, o cronista Leven Vampré (1891-1956), que assumia a função de gerente da Revista. Os fotógrafos, o gravador e o governador, assim como muitos outros paulistas, viam de modo muito favorável a publicação, uma vez que ela representava de forma positiva o desenvolvimento progressivo do Estado. A administração de Salles Oliveira significava a vitória e a vingança de São Paulo, que se sentia traído desde a revolução de 1930. A Revista divulgava as realizações do governador, "civil e paulista", dentre as quais destacavam-se aquelas ligadas à modernização do Estado, desde a produção agrícola e industrial, o transporte, as obras públicas, a urbanização de sua capital, as instituições de formação e pesquisa, os aparatos de garantia da ordem pública, a assistência a filhos de operários e aos jovens paulistas até o implemento da educação do nível infantil ao superior. Para o governo, o ponto principal destas reportagens era a divulgação do desenvolvimento econômico de São Paulo e a prestação de contas de Salles Oliveira junto às instâncias que o haviam colocado e o sustentavam no poder. Atribui-se à S.Paulo um caráter semi-oficial pelo fato de não haver publicado nos seus exemplares créditos editoriais ao governo ou secretaria a ele ligada; isto não objetiva negar a vinculação da redação ao governador e sim diferenciar a publicação dos tradicionais álbuns editados desde o início do século XX com a finalidade de fazer propaganda do Estado (KOSSOY, 2004, p. 430). Além disso, é notável que o direcionamento da Revista seguia as escolhas dos diretores verdamarelos, que representavam o poder instituído mas que tinham à frente seus interesses particulares como a sustentação de suas carreiras públicas e a afirmação deles como intelectuais.

Alguns fatores específicos possibilitaram o surgimento de uma revista ilustrada no padrão da S.Paulo no Estado paulista em 1936; a necessidade de afirmação da identidade regional é um deles. Transformações de ordem econômica, política e 
social, como a abolição da escravatura, a República, a industrialização e a imigração, aceleraram a urbanização de algumas cidades brasileiras. A acumulação de capitais no Estado de São Paulo, devido, principalmente, à produção de café, impulsionou o crescimento acelerado de sua capital. A recente imprensa paulista nasceu com um restrito público leitor, pois eram poucos os alfabetizados na província: "a cidade letrada, ainda moldada nas tradições elitistas da colônia, enfrentaria inúmeros embates e desafios" (CRUZ, 2000, p. 43). A vida urbana criou novos projetos sociais, novas instituições e ampliou o círculo de participação na vida cultural.

Somente a partir de 1828, com a abertura da Faculdade de Direito do Largo de São Francisco, a cidade de São Paulo começou a ganhar espaços como casas livreiras, bibliotecas e as primeiras tipografias. Nas duas primeiras décadas do século XX a cidade de São Paulo deixou suas feições de povoado e rapidamente transformou-se em uma metrópole. A economia cafeeira trouxe consigo a imigração em massa e as ferrovias. Vários loteamentos foram abertos e o perímetro urbano se alargou depois de quase trezentos anos de estagnação. A cidade ganhou novos espaços de convivência e novos habitantes, entre eles, muitos imigrantes italianos, trabalhadores vindos do interior, mulatos e negros recém libertos. Estas modificações afloraram a necessidade de construção da identidade cultural da São Paulo moderna. A nascente imprensa tinha pouca penetração fora dos limites da elite da Faculdade, composta na sua maioria por homens. Segundo Cruz (2000, p. 66), a escrita e principalmente a palavra impressa estabelecem novas articulações no cotidiano da cidade. Por esta razão, as elites paulistas organizaram-se para a criação de estabelecimentos de ensino particular que suprissem as suas necessidades; ocorreu também a expansão do ensino público e aumentou a alfabetização da população em geral. Estas medidas educacionais visavam também difundir a ideologia dominante entre a população e, sobretudo, entre os imigrantes, fazendo-os conhecer a história do Brasil e do Estado de São Paulo. A partir da proclamação da República, as classes dirigentes paulistas tomaram a instrução pública como símbolo de progresso; a economia baseada no 
trabalho necessitava de mão de obra capacitada para as atividades produtivas. As palavras entravam no espaço urbano, a escrita aparecia em letreiros verticais na paisagem da cidade e os bambini ofereciam, pelas ruas, periódicos de diferentes órgãos de imprensa. A reportagem da S.Paulo "O sentido paulista da vida brasileira quer dizer: organização" investe na imagem da capital do Estado como símbolo de metrópole moderna e utiliza a fotomontagem para aproximar diferentes elementos que simbolizam o progresso de São Paulo. A organização é o possibilitador do desenvolvimento do Estado e o título sugere a elevação de São Paulo à categoria de nação, como se fosse um país dentro do Brasil.

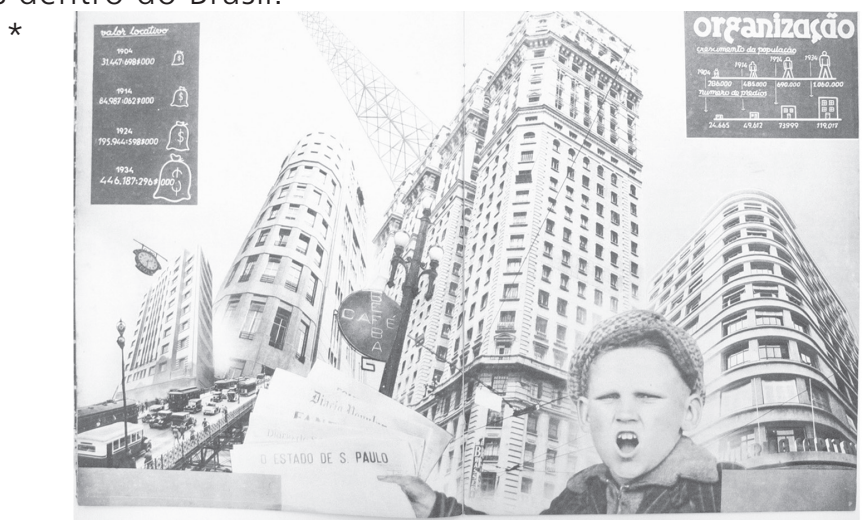

FIGURA 02 - reportagem de página dupla, $10^{a}$ e $11^{a}$ pág. $(63 \mathrm{~cm} \times 45 \mathrm{~cm}$ aprox.), S.Paulo 01, janeiro de 1936. Acervo: Instituto de Estudos Brasileiros, IEB/USP.

O surto de revistas ilustradas no início do século XX vem da demanda de leitores não alfabetizados, assim como a variedade de assuntos num mesmo periódico visava o alcance de diferentes tipos de público, a imagem nestas revistas cumpria uma função estratégica. Apesar dos investimentos da elite paulista no ensino público, estas medidas eram recentes e limitadas. Havia ainda um crescimento populacional acelerado devido à imigração em massa, o que aumentava mais o número de analfabetos na cidade.

O crescimento da imprensa ilustrada está vinculado ao desenvolvimento da indústria gráfica. A difusão de reproduções 
fotográficas em periódicos dependia de uma técnica que pudesse manter os nuances da imagem aliada a uma ampla tiragem a baixo custo. A forma e circulação de um periódico ilustrado também eram determinadas pelo menor tempo possível de sua produção. A impressão em meio tons e as máquinas rotativas vieram suprir algumas destas necessidades. A abordagem da informação em um diário, semanário ou mensário difere-se não apenas pelo tempo de produção, mas principalmente pelo tempo de sua permanência em circulação. Podemos dizer que até determinado momento a escolha era limitada pela técnica, logo depois, passou a ser consciente e controlada de acordo com as características desejadas para o periódico e seu público alvo. A revista S. Paulo surgiu originalmente como um mensário que possui um denso conteúdo visual. O tempo de sua permanência em circulação possibilitava que este conteúdo fosse lido também complementado pelo texto; à distância, a Revista pode ser interpretada pelas grandes ampliações fotográficas e pelos títulos das reportagens. As capas da S.Paulo nas bancas podiam assemelhar-se a um cartaz na paisagem urbana, grande no formato $(31,5 \mathrm{~cm} \times 45 \mathrm{~cm})$ e quase nenhum texto. A carga ideológica da Revista, a divulgação da ideologia da marcha, é baseada primordialmente na palavra escrita. Isto revela os limites do pensamento dos diretores quanto à funcionalidade da imagem fotográfica, por mais que se afirmem pelo moderno eles sentiram necessidade de trazer o discurso também numa forma tradicional.

A imprensa carioca e paulista se modernizavam com a aquisição de novas máquinas e a introdução de novas técnicas no ritmo do crescimento de suas capitais. A cidade de São Paulo seguia de perto as inovações técnicas e o maquinário era adquirido com o capital advindo da produção cafeeira. Na primeira década do século XX, São Paulo já tinha publicações ilustradas de qualidade, como a "São Paulo Magazine", de 1906. A pesquisadora Ana Luiza Martins (2001, p. 187) chama a atenção para o descompasso entre técnica e conteúdo nas publicações paulistas ilustradas destas primeiras décadas. Havia conexões com a modernidade, os recursos eram de vanguarda, no entanto, permanecia o cultivo às tradições e a temática ufanista 
no conteúdo. O rápido crescimento do estado e de sua capital criou uma repentina mudança na vida paulista, que pode ser traduzida neste aparente desequilíbrio entre a tradição e o moderno nas publicações. A historiografia paulista foi responsável pela elaboração da modernidade de São Paulo, projetada sobre a invenção do passado colonial. A divulgação desta historiografia dá-se por meio de projetos de cunho pedagógico e propagandístico. Podemos incluir a revista S.Paulo no rol de experiências que promove, além de outros conteúdos, esta tradição de modernidade. A imagem mostrou-se mais eficaz que a letra e a fotografia potencializou a difusão das informações. A revista ilustrada era a forma perfeita para mostrar o progresso do Estado e propagar mensagens numa sociedade sem tradição de leitura.

A construção gráfica da S.Paulo e sua função de divulgar as obras do governo permitem aproximá-la de um repertório visual vanguardista. O programa editorial da Revista a difere do que conhecemos por fotojornalismo ou fotoreportagem modernos; pode-se dizer que ela dialoga com experiências dadaístas e construtivistas em algumas aplicações da fotomontagem e, em especial, com a revista russa SSSR na stroike (URSS em construção). A S.Paulo é uma experiência pontual e relevante para a história da imprensa ilustrada brasileira. Ela é também de interesse para a história da fotografia no Brasil; o pesquisador Boris Kossoy (2004) fala sobre o consenso da ausência da fotografia enquanto manifestação estética moderna no Brasil até o surgimento das propostas de Geraldo de Barros, em fins dos anos 1940, e lembra as produções isoladas como as fotomontagens de Jorge de Lima e a proposta da revista S.Paulo (2004, p.446-447).

A "Revista da Semana" (Rio de Janeiro, 1900), de Álvaro Teffé, pode ser apontada como marco inicial do surto de revistas ilustradas no país e já empregava métodos fotoquímicos de reprodução. A fotografia já havia sido adotada pela propaganda política nas primeiras décadas do século $X X$, como no caso do suplemento da revista "Illustração Paulista", número 67, de 1912, sobre o governo de Rodrigues Alves (apud. MARTINS, 2001, p. 196). O que destaca a S.Paulo entre outras publica- 
ções não é o uso da imagem fotográfica, mas a forma como ela foi usada. A Revista traz em suas páginas um conteúdo tradicional e conservador envolto por uma visualidade ousada e moderna caracterizada pelo uso da fotomontagem.

Não foi por acaso que ao escrever um texto sobre fotografia , o crítico alemão Siegfried Kracauer (1889-1966), em 1927, ressaltou a sua aplicação em revistas ilustradas. Ao referir-se à fotografia, Kracauer faz uma crítica à sociedade em que vivia. Ele refere-se ao gênero de revistas de variedades que se difundia entre uma ampla gama de leitores. A "greve de conhecimento", a que o crítico se refere no texto, é acarretada pela invenção das revistas ilustradas e sua permanência nas mãos das classes dominantes. Segundo Kracauer, devido ao consumo de revistas de colunismo social o público vê o mundo sem realmente percebê-lo. O autor critica a sedimentação de uma postura passiva diante da imagem, que leva o leitor a não sentir a necessidade de compreender as justaposições de conhecimentos que a envolvem. Esta postura diante de uma revista ilustrada de propaganda política, ou de outras formas de imagem como o próprio mundo dos objetos, tem por trás comprometimentos sociais mais graves. Diante de uma sociedade que cada vez mais experimentava o mundo por meio de reproduções fotográficas difundidas em massa, Kracauer pôde afirmar que "nunca houve uma época tão bem informada sobre si mesma" ao mesmo tempo em que "nunca uma época foi tão pouco informada de si mesma" sem que uma afirmação anulasse a outra. O depoimento de Kracauer revela a proliferação de imagens fotográficas na imprensa ilustrada; a fotografia é entendida neste tipo de publicação como uma imagem testemunho. A aparência de realidade da imagem fotográfica causa a impressão equívoca de verdade e acaba por esfriar as experiências humanas. Reproduções do mundo podem ser colecionadas em miniaturas; estas aquisições fotográficas satisfazem a necessidade de consumo da sociedade capitalista e os impulsos de realização.

O uso da fotografia por instituições ligadas à ordem, desde o seu surgimento, contribuiu para que ela passasse a ser 
apreciada como prova. Segundo Susan Sontag (2004), a visão "realista" do mundo é compatível com a burocracia, por isso a industrialização da fotografia permitiu o rápido estabelecimento de um modo racional de gerir a sociedade a partir da elaboração de um inventário do mundo; "as fotos foram arroladas a serviço de importantes instituições de controle, em especial a família e a polícia, como objetos simbólicos e como fonte de informação" (2004, p. 32). Os valores documental e testemunhal da fotografia também foram explorados desde os primórdios pelas ciências médicas, no entanto, e contraditoriamente, até poucas décadas atrás não se entendia a fotografia como um tipo de documento histórico. A historiografia considera hoje como documento, além da escrita, a fotografia e outras espécies de imagens respeitando as características singulares de cada tipo.

Da fotografia são comumente cobrados valores de verdade, mesmo sendo cotidianas e familiares as formas de intervenção na imagem. Roland Barthes (1915-1980), em entrevista, afirmou que "a fotografia é vítima do seu sobrepoder; como tem fama de transcrever literalmente o real ou uma parcela do real, não nos questionamos sobre seu verdadeiro poder, sobre as suas verdadeiras implicações." Para ele, há uma dupla visão da fotografia; de um lado ela é vista "como uma pura transcrição mecânica e exata do real. [...] Esta é evidentemente uma posição excessiva porque mesmo uma fotografia de reportagem implica uma elaboração, uma ideologia das perspectivas"; de outro, "tem-se a chamada fotografia de arte -, o que é também um outro excesso, pois é evidente que a fotografia não é arte, no sentido clássico do termo" (1995, p. 386).

Segundo o fotógrafo Benedito Junqueira Duarte, a S.Paulo "dava valor absoluto à fotografia, [...] porque era a própria fotografia que falava por si [...], ela teve não apenas um aspecto de atualidade, mas reuniu também o seu aspecto artístico, o seu aspecto técnico e o seu aspecto sociológico que é o final de todo valor fotográfico." A imagem fotográfica é de suma importância no entendimento das reportagens da revista S.Paulo; a fotografia estrutura a diagramação da publicação. Segundo uma visão positivista da história, a credibilidade teste- 
munhal da fotografia estaria em sua objetividade, partindo-se deste atributo, a história poderia ser remontada a partir destes fragmentos de aparência "realista". Segundo esta visão é que a redação da revista S.Paulo, no primeiro exemplar, atribuiu à fotografia do periódico a qualidade de "espelho" da realidade, pois se baseiam na fidelidade aparente da fotografia e não no conteúdo interpretado das imagens. Na Revista, mesmo a fotomontagem, foi utilizada na maioria dos casos mantendo-se a perspectiva naturalista e a hierarquia dos planos; a ela não corresponde uma ruptura de significado e desmembramento da forma. Helio Lobo, da Academia Brasileira de Letras, relatou no exemplar 09, sua interpretação sobre o uso da fotografia na Revista: "São Paulo é a flor da civilização brasileira. Pela sua expressão espiritual e material [...]. Faltava, porém, ao Estado um orgão que fotografasse para os outros e para o exterior essa admiravel actividade. São Paulo [...] em tudo [coloca] o retratista á altura do retratado." Para Lobo, fotografar significava fazer uma descrição fiel do objeto, deste modo a Revista foi elogiada como um "espelho", um testemunho fiel do desenvolvimento material do Estado. A diagramação da S.Paulo podia ser ousada até o limite em que os diretores julgavam possível manter a objetividade pretendida por eles com o uso da fotografia.

Sabe-se que desde sempre a fotografia pôde ser manipulada, seja antes ou depois da tomada, seja na sua articulação com outros elementos (texto, outras imagens, o modo como é mostrada e onde). A fotografia de imprensa agrega vários filtros culturais, o primeiro deles é o próprio fotógrafo, seguido do veículo no qual está impressa e do texto que a acompanha (artigo, legenda, manchete), entre outros. A pós-produção (KOSSOY, 2000, p.54) pela qual passaram as fotografias da S.Paulo é uma das chaves de entendimento da publicação. O trabalho de montagem e diagramação das páginas da Revista e o próprio formato dos exemplares agem sobre sua mensagem. A constituição gráfica da S.Paulo vai além da constatação das fotomontagens e da adaptação de imagens fotográficas ao espaço pré-fixado de uma página ou de blocos de texto. A Revista não possui homogeneidade visual, esteve aberta a expe- 
rimentações e explorou a articulação de diferentes elementos gráficos. A programação visual da S.Paulo era passível de modificações tendo alguns elementos constantes: linhas verticais e horizontais, texto em negativo, título em fontes grandes, reportagens de página dupla e suplementos, utilizados com variações. Não havia rigidez na programação visual, inclusive a capa sofreu pequenas mudanças durante o período de publicação da Revista. Esboça-se a criação de uma identidade visual, identificável, por exemplo, nas reportagens sobre a produção de "café fino", contudo, o conteúdo não era configurado de forma homogênea.

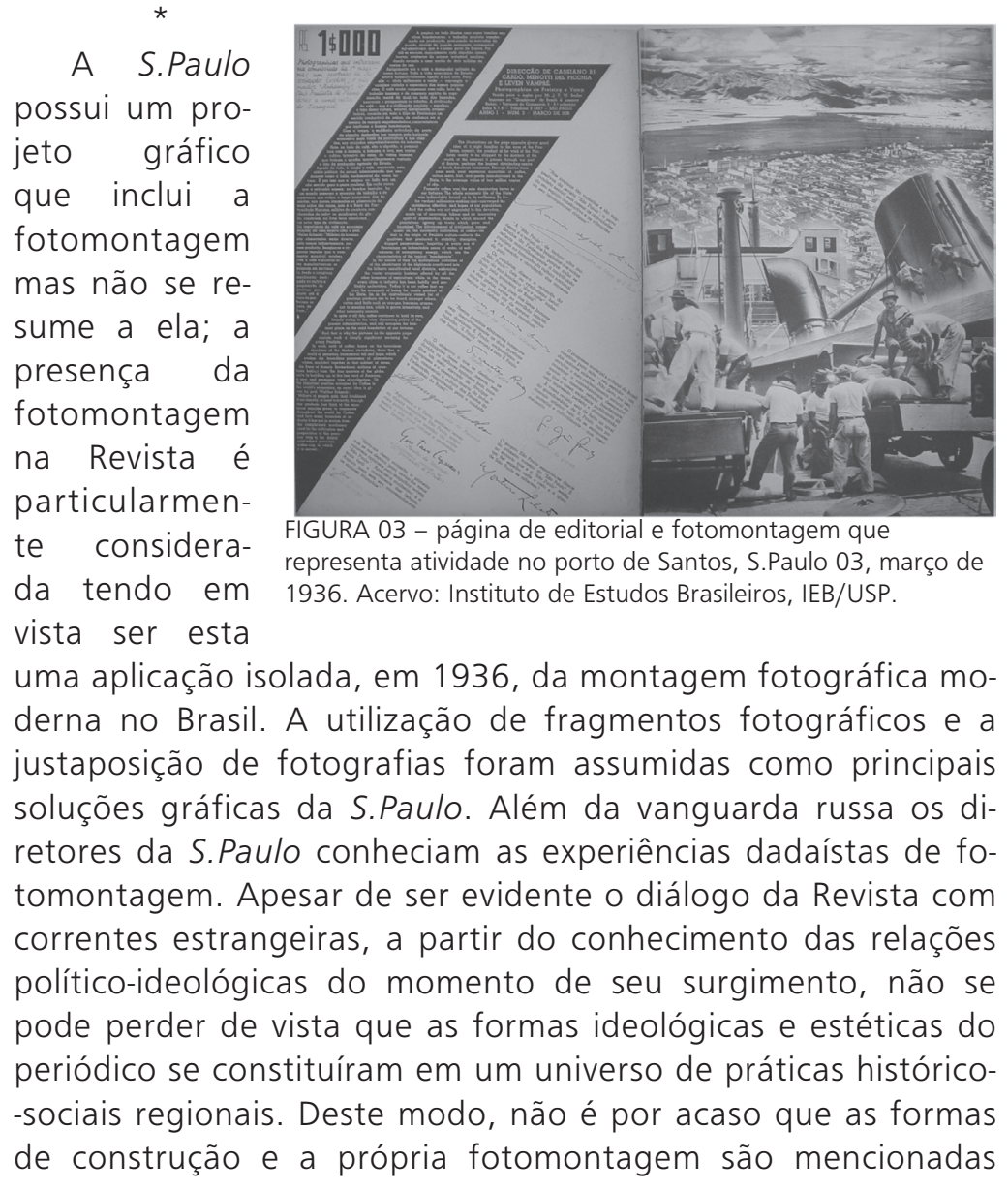


com referências estrangeiras, mas não puderam ser aplicadas na prática dentro dos mesmos conceitos.

Cassiano Ricardo, em suas memórias, atribuiu valor artístico e moderno à S.Paulo graças às fotomontagens de Lívio Abramo (1970, p. 69); o memorialista credita o diferencial da Revista à adoção da fotomontagem. Em pelo menos dois poemas posteriores, 1956 e 1971, Ricardo usa o termo como título; em

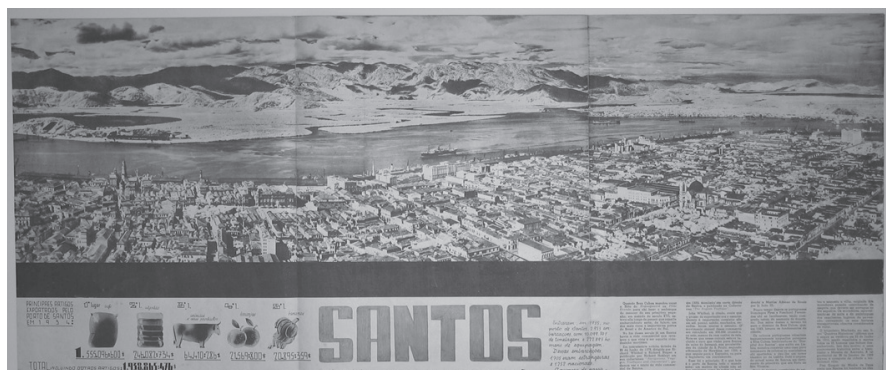

FIGURA 04 - suplemento da reportagem sobre a cidade de Santos, nesta fotomontagem pelo menos dois negativos foram justapostos para formar o panorama do porto $(94,5 \mathrm{~cm} \times 45 \mathrm{~cm}$ aprox.), S.Paulo 04, abril de 1936. Acervo: Instituto de Estudos Brasileiros, IEB/USP.

ambos o conceito de fotomontagem, passa pela idéia de construção de uma visualidade anteriormente ignorada ou impossível de existir de outro modo.

$\mathrm{Na}$ S.Paulo o uso da fotomontagem recria a espacialidade das fotografias nas páginas do periódico; elas surpreendem na forma mas não apresentam-se como revolucionárias ou subversivas no conteúdo. A diagramação de uma reportagem comporta muitas vezes sobreposição, recorte e justaposição de fotografias e fotomontagens. Na Revista, a fotomontagem é aplicada mais no sentido de enfatizar uma informação já contida na fotografia isoladamente; as montagens fotográficas alteram a forma original das imagens, mas não efetivamente o sentido.

São comuns nas reportagens da Revista mon-

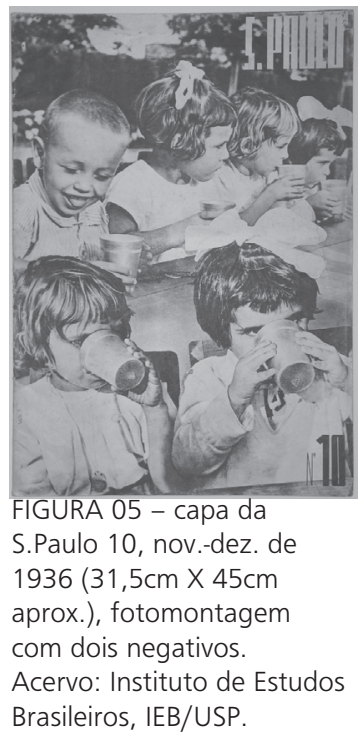


tagens fotográficas que apenas acrescentam elementos à composição ou que transformam a imagem da fotografia tal qual foi tirada pelo fotógrafo. Isto acontece na capa do exemplar 10, onde duas fileiras de crianças são aproximadas na montagem de dois negativos, os quais foram localizados no Arquivo de Negativos do Munícipio e são da autoria de BJ Duarte.

Nota-se na S.Paulo também a presença da fotomontagem no sentido de construção e de engenharia. Nas reportagens cujo conteúdo temático é a construção, verifica-se como as imagens de máquinas e de estruturas de arquitetura possibilitam a exploração de uma estética moderna. A construção é um elemento presente nas imagens fotográficas e na elaboração das páginas da Revista, o construtivo está tanto na montagem técnica quanto na produção da mensagem. A reportagem sobre a fábrica de cimento 'Votorantim' apresenta uma fotomontagem com grandes ampliações fotográficas.

O tubo que atravessa a composição remete o leitor ao universo da máquina, à direita uma engrenagem gigante avança sobre a

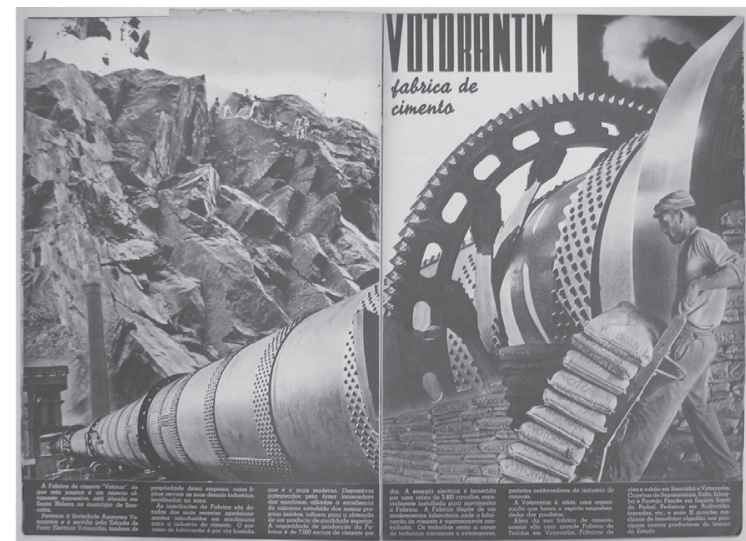

FIGURA 06 - reportagem de página dupla sobre a

'Votorantim', 18a e 19a pág. (63cm X 45cm aprox.), S.Paulo 08, agosto de 1936. Acervo: Instituto de Estudos Brasileiros, IEB/

jazida de

calcário; a imensidão da pedreira é subjugada pelo avanço do instrumento assim como a dimensão do homem é minimizada pela grandeza da natureza. Esta última apresenta-se dominada pelo humano aliado a suas máquinas, este é o grande símbolo do progresso, por isso o agigantamento desta estrutura que invade a montagem. Se a fotomontagem tem por trás de seu conceito a aproximação do universo da máquina e do homem, 
na Revista, devemos acrescentar a esta junção a natureza, que é elemento presente nas montagens fotográficas e na ideologia conservadora dos 'verdamarelistas'.

A direção escolheu utilizar a fotomontagem tendo conhecimento de seu potencial subversivo; contudo, ao aplicá-la sob o teor ideológico dos diretores criou-se uma fotomontagem técnica. Nas composições, como deve ser dentro de uma tradição conservadora, não há fotomontagem no sentido radical de desmembramento ou de descontinuidade.

O termo fotomontagem foi cunhado entre os artistas dadaístas de Berlim; dentre eles, por sua característica política, destacam-se John Heartfield (1891-1968), Hannah Höch (18891978) e Raoul Hausmann (1886-1971). A idéia do artista 'foto-montador', tirada do operário numa linha de montagem industrial, qualifica bem a fotomontagem dentro do universo da máquina e da arte. Este conceito surgiu na segunda metade da década de 1910 e diferencia-se da colagem cubista no uso da fotografia na formação estrutural da composição. A fotomontagem vincula-se à idéia de construção, onde o artista que se dedica a ela é comparado a um engenheiro, um montador. Na Feira Internacional Dadá de maio de 1920 o termo fotomontagem não era muito comum; a primeira grande exposição de fotomontagem foi celebrada em Berlim em 1931. A fotomontagem com função político-ideológica tem na figura de John Heartfield seu principal adepto. Ele a empregou como instrumento de sátira sócio-política e contra-propaganda nazista na Alemanha, a partir dos anos 20. Suas fotomontagens de sátira à política alemã foram apresentadas nas edições da revista ilustrada AIZ (Arbeiter Illustrirte Zeitung) entre 1930 e 1938 e outros periódicos. Nas fotomontagens de Heartfield, o texto é muito significativo, as frases ácidas de críticas à sociedade alemã e ao nazismo fazem parte da imagem. Sempre que ele expunha suas fotomontagens fazia questão de ter um exemplar da revista para deixar claro que não eram obras únicas e sim que foram feitas para o grande público com a função de propaganda política. As fotomontagens de Heartfield propunham subverter a ordem. 
A fotomontagem também foi utilizada pelo construtivismo russo ligada aos ideais da Revolução Socialista de 1917. Alguns artistas da vanguarda russa, entre eles Gustav Klutsis (18951944), Aleksander Rodchenko (1891-1956), Varvara Stepanova, El Lissitzky (1890-1941) e Sophie Küpper participaram da propaganda do governo soviético, inclusive durante o realismo socialista instituído por decreto em 1932. O envolvimento destes artistas na causa da Revolução e depois a serviço das necessidades da elite stalinista em formação mostra a adaptação da estética revolucionária em estética oficial. O engajamento político destes artistas, segundo Annateresa Fabris, alcança uma esfera mítica: Klutsis colabora para criação do mito do novo mundo e o papel desempenhado pelo novo homem neste mundo; Lissitzky contribui para a formação do mito da origem, uma contraposição entre a cegueira do passado e o gesto inaugural de Lenin, que aponta o futuro; Rodchenko confere um significado regenerador ao emprego de mão de obra de presos nas grandes obras do Estado soviético (2005, p.130). Não é possível negar o envolvimento destes artistas com o governo de Stálin e sua elite; eles contribuíram na construção da imagem de um país sem conflitos, sem contradições e orgulhoso de si mesmo.

As montagens fotográficas ou fotomontagens surgem como uma possibilidade da imagem "falar" de uma maneira nova (ADES, 2002, p. 20) e podem ser relacionas com as mudanças sofridas pela fotografia (microscopia, radiografia e vista aérea) durante a Primeira Guerra Mundial. Neste estudo, usa-se o termo fotomontagem aplicado às composições onde há justaposição de fragmentos fotográficos; reconhece-se a atuação dos elementos gráficos e textuais, uns sobre os outros, na produção da mensagem. Assume-se que na revista S.Paulo há a utilização de uma fotomontagem técnica. Aplica-se o termo fotomontagem na Revista às composições que possuem a idéia de construção, mas não necessariamente como indicativo do caráter subversivo da mensagem.

A fotomontagem utilizada por Alecksander Rodchenko o aproxima cada vez mais das diretrizes oficiais, "cria-se, assim, uma nova modalidade de composição: [Rodchenko] deixa de 
lado a fragmentação das primeiras experiências e estrutura suas fotomontagens a partir da combinação de fotografias ou conjuntos de fotografias individuais." (FABRIS, 2005, p.113). Rodchenko e Lissitzky, ao lado de suas respectivas esposas, formaram as duas equipes de artistas vindos da vanguarda russa que colaboraram assiduamente para a revista SSSR na stroike. Nesta publicação, a fragmentação característica da fotomontagem construtivista recebeu críticas diante da necessidade de clareza e de síntese na comunicação; assim, a revista perdeu, por ordem oficial, seus aspectos de vanguarda.

Na busca por entender a existência da revista S.Paulo, em seu formato peculiar para o que se tem conhecimento da imprensa ilustrada brasileira no período, ficou claro que seu projeto dialoga com outras publicações. Em depoimento publicado no exemplar 06 da S.Paulo, Lourival Fontes (1899-1967), na época diretor do Departamento de Propaganda e Difusão Cultural - DPDC, afirma que a "'S. Paulo' é uma revista que ultrapassa quaesquer outras publicações do genero feitas no Brasil, só sendo comparavel ás publicações editadas no mesmo sentido pela Russia, Italia e Alemanha.". A esta afirmação somam-se as de Cassiano Ricardo e do jornalista Paulo Duarte (18991984) para que possamos concluir que a S.Paulo foi pensada a partir de um modelo de revista de propaganda soviética. Cassiano Ricardo diz, em seu livro de memórias, que a S.Paulo era uma revista espetacular de "divulgação dos empreendimentos bandeirantes" e que causou sensação quando remetida ao exterior, sendo "talvez superior à revista do mesmo tipo publicada na Rússia" (1970, p. 69). Para o poeta-diretor a S.Paulo era uma realização artística, de divulgação do crescimento e dos feitos do estado, com fotografias modernas, fotomontagens e estatísticas ilustradas.

Paulo Duarte (1976), em seu livro de memórias, afirma que a revista S.Paulo era paráfrase de uma publicação russa chamada "URSS", de propaganda das realizações comunistas. Ele se refere ao periódico paulista como uma revista ufanista e de patriotismo exaltado, que imita a propaganda russa e faz uso de muita imagem, como deve ser num país onde o índice de 
analfabetismo é muito alto .A S.Paulo, nas palavras de Paulo Duarte, era bem feita, mas imitava uma revista de Moscou: "[a 'URSS' tinha] formato grande, fotografias espetaculares, dava até vontade da gente ir para a Rússia. Pois a revista S.Paulo talvez seja capaz de dar vontade de vir para o Brasil, sendo paráfrase da outra." (1976, p. 141).

A revista soviética de propaganda a qual os comentadores acima se referem foi identificada neste estudo com a revista SSSR na stroike (URSS em construção, 1930-1941 e 1949). Após o confronto entre as características desta publicação com as da S.Paulo indentificou-se que, em diferentes aspectos e guardadas as devidas diferenças, estes dois periódicos possuem características comuns. Dentre elas a imagem era o dispositivo discursivo considerado o mais eficaz pelos diretores dos dois periódicos, aceito com menor resistência que o discurso escrito e capaz de ser compreendido pelo grande contingente de analfabetos existentes tanto na URSS quanto no Brasil.

A SSSR na stroike era uma publicação de propaganda do regime soviético direcionada ao público interno e externo; circulava regularmente em russo (ссср на стройке em letras cirílicas e SSSR na stroike em letras latinas) e em mais três idiomas estrangeiros: francês, alemão e inglês e, a partir de 1938, também espanhol. O grande interesse do Estado soviético era econômico, por isso nos dois primeiros anos da revista edições de luxo foram sistematicamente direcionadas a investidores estrangeiros com a finalidade de atraí-los ao país. A revista foi concebida originalmente como suplemento ilustrado da revista literária Nashi dostizheniia (Nossas conquistas, 1929-1937), bastante popular, fundada pelo escritor russo Maksim Gorkii e editada pela Gosizdat (Casa editorial do Estado da União Soviética). A Nashi procurava enfatizar que cada pequena parte realizada pelos trabalhadores era importante para o grande projeto de construção do Estado Soviético, como no texto "Sobre pequenas pessoas e seus grandes feitos" (1929 apud. WOLF, 2000, p.54); a revista divulgava as conquistas econômicas e culturais da URSS utilizando linguagem extensivamente acessível e sempre de forma positiva.

Segundo a pesquisadora Erika Wolf, o conceito deste su- 
plemento ilustrado foi desenvolvido inicialmente com o grupo Ogonek, companhia editorial que lançou em abril de 1923 a primeira revista ilustrada da URSS e, em 1926, criou uma revista especializada em fotografia, Sovetskoe foto. Em 1929, o grupo possuía grande representatividade na imprensa popular do país. O seu presidente, o jornalista Mikhail Koltsov foi um dos responsáveis pela implantação das bases do fotojornalismo moderno na URSS (WOLF, 2000, p. 57). No entanto, duvidou-se da capacidade do grupo Ogonek desenvolver uma publicação de alta qualidade técnica, uma vez que dedicava-se a periódicos populares. Além disso, pareceu mais conveniente vincular a revista SSSR na stroike a Gorkii, o mais conhecido escritor russo do período. O fundador da Nashi foi de imediato contrário ao suplemento, "Pequenas imagens, em geral, não são convincentes. Para ser perfeitamente franco, esta empreitada não faz sentido para mim e não é do meu gosto." (1929 apud. WOLF, 2000 , p.58). Gorkii voltou atrás em seguida; no entanto, durante as negociações do suplemento a publicação transformou-se numa revista independente. Havia uma incompatibilidade entre a Nashi, cuja função era pedagógica junto às massas de trabalhadores da URSS, e a SSSR na stroike, cujo plano inicial visava o leitor estrangeiro. O primeiro editor chefe da SSSR foi Georgii [lurii] L. Piatacov, presidente do Gosbank (Banco do Estado da URSS), por isso afirma-se que motivações financeiras foram consideradas na escolha por uma distribuição externa da revista. A primeira edição da SSSR foi lançada em dezembro de 1929 pela Gosizdat em quatros idiomas (francês, alemão, inglês e russo). As mesmas chapas de impressão do material fotográfico eram reaproveitadas para as diferentes versões e era feita uma sobre impressão dos textos nos respectivos idiomas. Segundo Wolf, não há diferenças significativas nos conteúdos das versões da primeira edição, exceto o slogan "Trabalhadores do Mundo Branco", que aparece apenas na versão russa (2000, p.60). A revista SSSR na stroike tinha edições em diferentes idiomas para garantir a propaganda internacional do regime soviético e criar uma imagem positiva do país.

O uso da imagem fotográfica na revista SSSR na stroike foi evocado como testemunhal das condições de vida na URSS, 
"nós decidimos nos voltar para o desenho da luz, para a palavra do sol - para a fotografia. Vocês não podem acusar o sol de distorções, o sol ilumina o que existe como existe.". O autor deste prefácio é Gorkii que politizou através do texto o conteúdo visual da revista. Ele convoca a fotografia, tal qual o cinema, a servir sistematicamente a construção da URSS por meio de representações fotográficas dinâmicas e acessíveis a todos os interessados (1929 apud. WOLF, 2000, p.61). A SSSR era uma revista fartamente ilustrada com fotografias e os textos compunham apenas uma pequena parte das reportagens, títulos e legendas. A intenção era, por meio da imagem, vencer a resistência, principalmente do leitor estrangeiro, ao discurso textual, muito mais passível de crítica. Em carta a VOKS (União das Sociedades para Relações Culturais no Exterior), um professor do departamento de psicologia da Universidade de Londres, declara a satisfação de receber a SSSR, com "fotografias e reproduções excelentes" e se queixa dos panfletos de propaganda política que também recebia (1931 apud WOLF, 2000, p.68). Para o professor a fotografia não era percebida como propaganda ideológica como os discursos escritos.

Durante os dois primeiros anos foram feitas edições de luxo e edições econômicas das versões estrangeiras da SSSR na stroike; as primeiras eram direcionadas a um grupo seleto de empresários e comerciantes e a segunda a trabalhadores e intelectuais. O preço da assinatura anual era o mesmo para os dois tipos de edição e o Gosbank promovia e monitorava a recepção da revista no exterior através da coleta de depoimentos de leitores estrangeiros; dois terços dos comentários eram de bancos e negociantes (1930 apud WOLF, 2000, p.64). Visando o público interno os exemplares eram lançados em datas significativas, principalmente, para a elite stalinista, que ganhava força nos anos 1930. A SSSR era um dos periódicos mais caros em circulação no país e cada vez mais se tornou um item destinado à nova elite. Em 1934 começa a aparecer versões de luxo da SSSR especial para o leitor russo. No ano seguinte um álbum foi organizado, em edição limitada, contendo todas as versões luxo de 1935 (WOLF, 2000, p.72), isto enfatiza o papel da revista como objeto de consumo. Se por um lado a 
fotografia havia sido escolhida para diminuir a distância entre a publicação e o grande número de russos analfabetos - segundo os construtivistas ela era adequada à propaganda visual porque era produto de uma máquina, universalmente praticável e amplamente compreensível - as edições de luxo e as assinaturas cada vez mais caras excluíam o trabalhador da condição de leitor da SSSR.

Em 1931, John Heartfied passou uma temporada em Moscou e foi o responsável pela edição da SSSR na stroike do final do ano, que é um marco na estrutura da revista. Ele modificou o tratamento gráfico da SSSR levando-o a uma estética mais arrojada; Heartfield utilizou uma impactante fotomontagem na capa e empregou uma estrutura que integrava efetivamente texto e imagem no layout interno. A partir desta edição a SSSR tornou-se mais sofisticada graficamente; de acordo com o pesquisador Rune Hassner, sob a perspectiva de imagens e de layout, o período de maior interesse desta revista soviética vai até 1936, quando o editor chefe G. L. Piatacov foi substituído (ÖSTERLUND, 2006). O artista El Lissitzky começou a colaborar com a revista SSSR em 1932 e Aleksander Rodchenko em 1933. Eles colaboraram frequentemente para a revista e foram os responsáveis pelas edições de luxo. Em abril de 1933, o amplo uso da técnica da fotomontagem na SSSR causava apreensão em membros do Comitê Central; "de acordo com a opinião geral do corpo editorial este design é, sem argumento, um sucesso, mas nós declaramos a necessidade de não usar excessivamente a fotomontagem, para que a revista não perca sua simplicidade e naturalismo." (apud. WOLF, 2000, p.73). A aplicação dos métodos de vanguarda na SSSR era endossada pelos editores desde que não rompessem a objetividade da fotografia com cortes abruptos e justaposições; os artistas seguiram estas determinações. As montagens permitidas e aplicadas na revista passaram a ser meramente técnicas, a fotomontagem construtivista deixou de existir e deu espaço à criação de uma fantasia visual do novo Estado soviético para a elite stalinista.

O surgimento da revista S.Paulo veio atender a demandas particulares do próprio estado e de intelectuais a ele ligados. 
Havia um desejo comum de divulgar entre paulistas, brasileiros em geral e estrangeiros o progresso do estado. Esta propaganda era também uma forma de reafirmação de São Paulo, que finalmente conseguira o seu interventor adequado. $O$ estado ressurgia com força econômia e política a despeito dos limites impostos pelo governo federal; a Revista era vitrine da vitória, tardia, do Movimento Constitucionalista de 1932. O conteúdo ideológico presente na Revista direcionava-se a um leitor paulista e/ou simpatizante com o estado e objetivava agregar novos parceiros de idéias. Os textos em português das reportagens apresentam-se carregados de regionalismo e nacionalismo ufanista segundo a ideologia conservadora do pensamento 'verdamarelo'. A imagem fotográfica como estrutura das reportagens era estratégia para que a Revista pudesse burlar algum tipo de resistência de opositores ao regionalismo e à ideologia da 'marcha' divulgados nas reportagens. A visualidade moderna despista o conservadorismo das idéias inseridas na publicação pelos diretores Cassiano Ricardo e Menotti del Picchia e reforçadas a partir do exemplar de junho de 1936, que preparou o leitor para a publicação do programa-manifesto do Movimento Cultural 'Bandeira' que apareceria três exemplares depois.

Existia por parte dos editores da S.Paulo a pretensão de torná-la uma revista de circulação internacional. Não há evidência de distribuição regular da Revista no exterior, mas remessas do periódico eram emitidas a leitores estrangeiros pela própria direção ou pelo gabinete do governador. A revista S.Paulo era bilíngue, português e inglês e podemos afirmar que a escolha deste idioma estrangeiro obedeceu a interesses econômicos. Salientemos que havia na época grande disseminação da cultura francesa no Brasil e do francês como segunda língua da elite nacional. De acordo com Roger Bastide, o francês era a língua dos salões, como o inglês era a língua do comércio (1973, p.207). As reportagens da S.Paulo, ao mesmo tempo em que prestavam contas do governador à elite que o apoiava divulgava suas boas realizações na administração do estado; elas traziam os números e cifras da economia paulista, que incluía o ensino público, o assistencialismo, as boas condições oferecidas ao trabalhador e ao agricultor/comerciante/industrial. O 
mundo da produção é representado de forma bastante positiva a fim de reforçar a idéia da inclinação paulista ao trabalho. A assistência do estado aos trabalhadores é pontuada na Revista e, no entanto, uma leitura crítica do periódico deixa claro que a publicação não se direcionava a este tipo de leitor. Toda a preocupação com o acabamento da S.Paulo visava impressionar as elites, econômicas e culturais; a chegada da mensagem da Revista aos trabalhadores era uma conseqüência prevista mas não determinante para os diretores. Nem todo conteúdo textual era traduzido para o inglês, privilegiando-se a tradução de gráficos, legendas e títulos. Estas informações podiam ser facilmente compreendidas mesmo por aqueles que não possuíam conhecimentos profundos sobre o estado de São Paulo. Já o conteúdo ligado à ideologia da 'marcha' e outros regionalismos não ganhavam versões inglesas, pois eles perdiam sentido sem uma introdução à historiografia paulista.

Os diretores da revista S. Paulo buscam na fotografia a mesma objetividade que os editores da SSSR na stroike. No editorial de apresentação da revista S.Paulo a redação fala da imagem, não especificamente da fotografia, mas ao tratá-la como 'espelho' remete às mesmas questões de fidelidade ao objeto de existência material do qual ela é reflexo e por isso testemunho fiel, como quiseram os editores da SSSR com a fotografia. A S.Paulo possui implementos gráficos de caráter vanguardista mas limitado; a fotomontagem que mantém o naturalismo da perspectiva monocular, ou que é meramente técnica é um exemplo.

Valendo-se da imagem fotográfica pelo que ela representa de moderno e da fotomontagem pelo que ela trás de dinamismo e impacto, a redação da revista S.Paulo fez transparecer as raízes conservadoras da ideologia defendida pelos dois diretores, em especial por Cassiano Ricardo.

O formato da revista S.Paulo, a técnica de impressão, as grandes ampliações fotográficas, as reportagens de página dupla e os suplementos desdobráveis, além da função do periódico, a colocam em diálogo com a SSSR na stroike.

A ousadia formal, que criou soluções gráficas singulares e o 
curto período de circulação da revista S.Paulo são aspectos que permitem considerá-la um projeto experimental. As incertezas do momento do surgimento da Revista permitiram a junção de uma equipe de redação heterogênea. A riqueza desta coleção, constituída de dez exemplares, está na complexa elaboração que justapõe elementos díspares num momento de indefinições no ambiente político e social do país.

A revista S.Paulo expõe o pensamento do grupo originário do 'verdamarelismo', vanguarda dissidente do modernismo paulista de 1922, presente na redação na atuação dos diretores Cassiano Ricardo e Menotti del Picchia, que expõe a raiz conservadora da ideologia da 'marcha para oeste' como difundida na publicação. A nova 'marcha' paulista, realizada pelo 'bandeirante moderno', é representada no periódico pela administração do governador Armando de Salles Oliveira. Ela surge no encadeamento das páginas da própria Revista, que possui momentos de descoberta nas páginas desdobráveis dos suplementos. Nas reportagens sobre grandes obras os valores heróicos dos bandeirantes surgem para representar o desbravamento e a dominação da natureza pelo trabalho do homem. A ordem e a disciplina das expedições coloniais são recolocados nas ações educativas e assistencialistas do estado moderno paulista. A duplicação de imagens e componentes gráficos nas reportagens da S.Paulo visa aumentar as dimensões dos objetos e eventos que, de outro modo, não seriam vistos com esta grandeza de valor; a constância temática reitera a visão paulista sobre a criação da identidade nacional. Grandes obras públicas e outras construções realizadas pela administração de Armando de Salles Oliveira são temas de várias reportagens da Revista. O senso de progresso passa pela idéia de construção e está nos assuntos fotografados, nas diagramações e nas fotomontagens. As obras de construção materializam na paisagem do estado o seu progresso; ele é construído na publicação por fragmentos fotográficos desta materialização.

A fotografia foi escolhida pelos artistas da vanguarda russa como o meio ideal, moderno e eficaz, na transmissão da mensagem da Revolução de 1917 num país de analfabetos e cuja extensão territorial acarretava grandes diferenças culturais. À 
fotografia dispensaram atenção especial e com ela exploraram as riquezas da montagem. As novas formas e as novas organizações tinham como concepção intelectual os predicados da Revolução; neste sentido, a fotografia era considerada o meio mais democrático para impulsionar o conteúdo social da arte. Tomada como ferramenta da elite stalinista a fotomontagem construtivista deixou de existir, como vimos no caso da revista SSSR na stroike.

Ao tratar de imagem fotográfica, recorte e construção, surge de imediato o termo fotomontagem. No entanto, destaca-se que as fotomontagens da S.Paulo cumprem muito mais a função técnica de adequação da imagem, modificando-a tal qual foi tomada pelo fotógrafo preservando referências tradicionais de perspectiva, profundidade e escala, que a criação de um outro significado. Nestas montagens as modificações não chegam a desconstruir as relações familiares entre os objetos representados; a justaposição e sobreposição de fragmentos de diversas imagens fotográficas que alteram a fotografia original não resultam num novo espaço. No editorial do primeiro exemplar a redação da S.Paulo refere-se ao "renascimento paulista". A gráfica moderna da Revista garante-se pelo próprio uso da fotografia, que já traz consigo uma afirmação de moderno. Ao exprimir o "renascimento paulista", caracterizado pela retomada política com o governador Armando de Salles Oliveira, a revista S.Paulo divulga a reconstrução do estado; cria a imagem
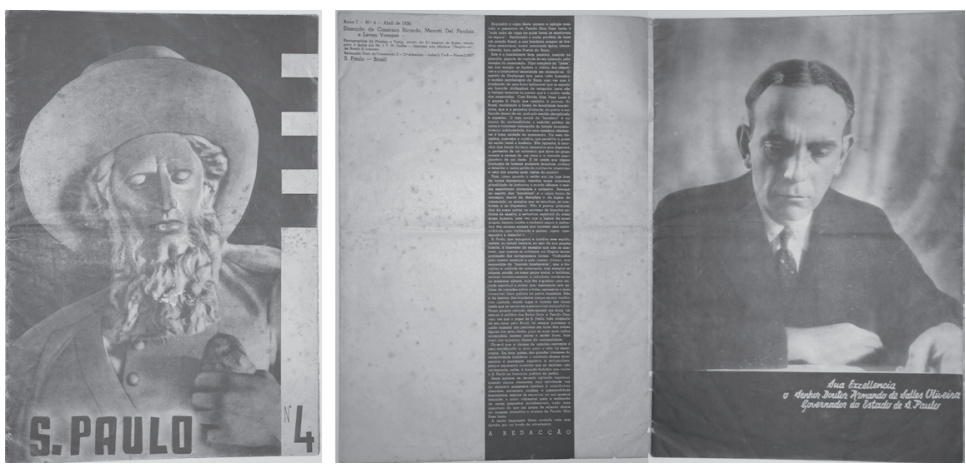

FIGURA 07 - Capa e 2ª e 3a páginas, S.Paulo 04, abril de 1936. O bandeirante Fernão Dias é sucedido por Armando de Salles Oliveira que representa o "bandeirante moderno". Acervo: Instituto de Estudos Brasileiros, IEB/USP 
da renascença de uma sociedade mítica existente no passado e não do surgimento de uma nova.

Constatou-se que a S.Paulo exprime dualidades e contradições em seu discurso. Na Revista, coexistem a tradição e o moderno sem a anulação de um conceito pelo outro; ao contrário, a própria tradição paulista é uma afirmação de sua modernidade. A S.Paulo apropriou-se de uma forma revolucionária para a divulgação de um conteúdo reacionário. A ideologia da 'marcha' significa a junção do pensamento 'verdamarelo' com a corrente liberal, em crise, do governador Armando de Salles Oliveira entre os anos 1935 e 1936. O potencial subversivo da fotomontagem, na revista S.Paulo, tomou o partido da ordem sob a disciplina imposta pela ideologia do periódico. De acordo com as bases da ideologia da 'marcha', a fotomontagem como ruptura e como fragmentação não seria eficiente na difusão do pensamento conservador do corpo diretor. A revista S.Paulo divulga a ideologia que vê o presente como continuidade do passado. Portanto, ao vincular a solução gráfica da Revista ao pensamento 'verdamarelo', a fotomontagem na publicação passa pela idéia de construção e pode-se afirmá-la como reconstrução - retomada de uma característica anteriormente presente.

Os termos vanguarda e marcha remetem-se ao universo militar; os ideólogos da Revista buscaram uní-los trazendo ao conteúdo do periódico a ousadia do movimento de frente levada a efeito na movimentação marcada e disciplinada de uma marcha. A ideologia da 'marcha' prega a uniformização do pensamento e a harmonia nacional; ela fez-se imbutida de valores universais e atendia a interesses de um grupo específico.

A imagem de uma modernidade criada pela revista S.Paulo não foi acompanhada pela transformação dos valores tradicionais que regiam a sociedade. A estética moderna se firmou num contexto em que não havia propriamente condições que a justificassem. A aparência de modernidade num contexto não preparado para as mudanças que ela propunha, gerou contradições e ambigüidades no panorama cultural brasileiro. Estas ambigüidades estão presentes na revista S.Paulo e na postura dos intelectuais com ela envolvidos. Na trajetória literária de Cassiano Ricardo é patente a escolha do poeta por um compro- 
metimento ideológico de associações políticas reacionárias sem abrir mão de um conhecimento estético moderno. Vale lembrar também como as referências estrangeiras foram adaptadas, às vezes mais por força do contexto que por vontade, à realidade

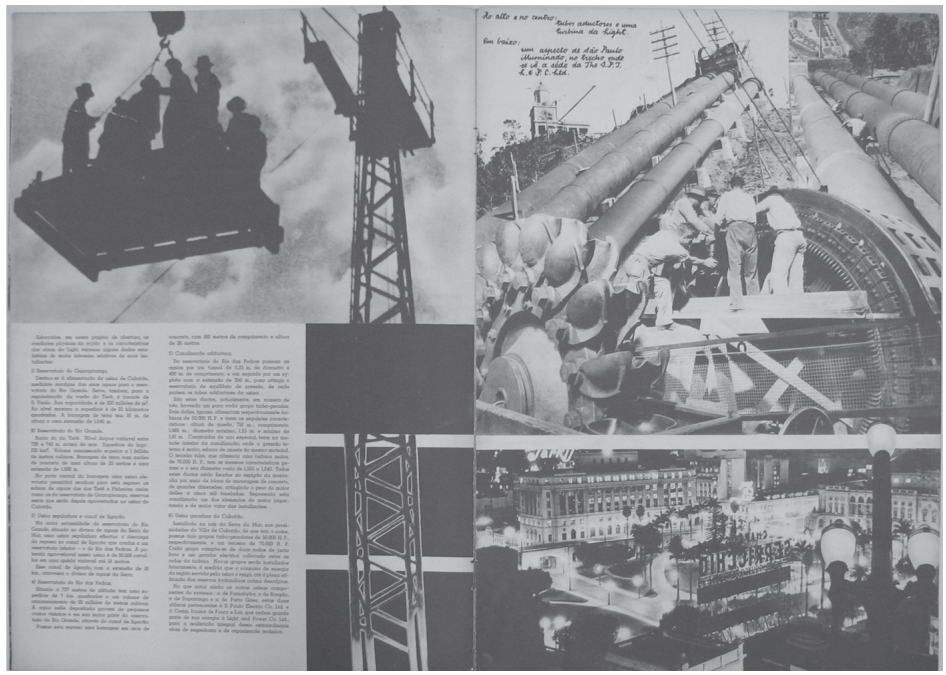

FIGURA 08 - continuação da reportagem sobre as obras da Light no Alto da Serra, o uso da imagem em negativo, no contra-luz e uma vista noturna do Anhangabaú fazem com que a diagramação remeta-se ao conteúdo da reportagem. S.Paulo 05, maio de 1936. Acervo: Instituto de Estudos Brasileiros, IEB/USP.

\section{Notas}

1. O nome da revista sempre será grafado desta maneira: S.Paulo ( $\mathbf{S}$ em caixa alta seguido de ponto seguido, sem espaço entre eles, pela palavra Paulo somente com o $\mathbf{P}$ em caixa alta, tudo em itálico).

2. A palavra revista grafada com $\mathbf{R}$ maiúsculo no meio da frase refere-se à revista S.Paulo.

3. Originalmente publicado na Frankfurter Zeitung, em 28 de outubro de 1927. Traduzido do original alemão por Carlos Eduardo Jordão Machado. Inédito.

4.- Depoimento de BJ Duarte ao MIS em 14 de maio de 1981, fita 'fotografia', lado 1 (continuação).

\section{Referências}

ADES, Dawn. Fotomontaje. Tradução Elena Llorens Pujol. Barcelona: Gustavo Gili, 2002. 176p.

BARTHES, Roland. Sobre a fotografia. In: BARTHES, Roland. O gro da voz. Trad. Anamaria Skinner. Rio de Janeiro: Francisco Alves, 1995. p.385-392. 
BASTIDE, Roger. Brasil, terra de contrastes. Tradução Maria Isaura Pereira Queiroz. 5 ed. São Paulo: Difusão Européia do Livro, 1973. 282p.

CRUZ, Heloísa de Faria. (org.). So Paulo em papel e tinta: periodismo e vida urbana 1890-1915. São Paulo: EDUC/ Fapesp/ Arquivo do Estado de São Paulo/ Imprensa Oficial SP, 2000. 224p.

DUARTE, Paulo. Memrias: os mortos de Seabrook. São Paulo, Hucitec, 1976. 442p. (v.4).

FABRIS, Annateresa. Entre arte e propaganda: fotografia e fotomontagem na vanguarda soviética. Anais do Museu Paulista, São Paulo, v.13, n.1, p.99132, jan.- jun. 2005.

KOSSOY, Boris. Realidades e fices na Trama fotogrfica. 2. ed. São Paulo: Ateliê editorial, 2000. 152p.

. Luzes e sombras da metrópole: um século de fotografias em São

Paulo (1850-1950). In: PORTA, Paula (org.). Histria da cidade de So Paulo, v.2: a cidade no Império. São Paulo: Paz e Terra, 2004. Capítulo 9, p.386 455.

MARTINS, Ana Luiza. Revistas em revista: imprensa e práticas culturais em tempos de república, São Paulo (1890-1922). São Paulo: Edusp: Fapesp: Imprensa Oficial, 2001. 600p.

ÖSTERLUND, Petter (editor). USSR in construction an illustrated exhibition magazine. Suécia: Fotomuseet Sundsvall, 2006. (WOLF, Erika (erika.wolf@ otago.ac.nz). "Recent Catalogue" e-mail para Marina Takami (marinatakami@yahoo.com.br). Enviado em 14 de fev. 2006.

RICARDO, Cassiano. Viagem no tempo e no espao: memórias. Rio de Janeiro: José Olympio editora, 1970. 334p.

SONTAG, Susan. Sobre fotografia.Tradução Rubens Figueiredo. São Paulo: Cia. das Letras, 2004. 224p.

WOLF, Erika. (erika.wolf@otago.ac.nz) When Photographs Speak, to Whom Do They Talk? The Origins and Audience of SSSR na stroike (USSR in Construction). Left History, vol. 6, no. 2, p. 53-82, 2000. "USSR in Construction" e-mail para Marina Takami (marinatakami@yahoo.com.br). Enviado em 18 de nov. 2005. 


\section{Marina Takami}

Mestrado em Estética e História da Arte (orientação: profa Helouise Costa, bolsa CAPES, USP, 2007). Bacharelado em Artes Plásticas (UNESP, 2002). Iniciação Científica (bolsa FAPESP, 2001/2002); menção honrosa melhor artigo XIV Congresso IC - UNESP. Participou: II Encontro de História da Arte (Unicamp, 2006); XVIII Encontro Regional de História (UNESP/Assis, Anpuh, 2006); VI Congresso de Estética e História da Arte (USP, 2006).

Rua Herculano de Freitas, 359/apto 84 - Bela Vista, São Paulo/SP, cep 01308-020. tels. 11-3237 3333/ 11-9536 2924. Universidade de São Paulo. marinatakami@yahoo.com.br. 